\title{
Suicide attempts in children and adolescents - risk factors, methods and management of suicidal patient
}

\author{
Izabela Marzec ${ }^{1}$, Katarzyna Zabłocka', Jan Stachurski² \\ 'Student Research Association of Pediatric Emergency Medicine, Medical University of Warsaw, Poland \\ ${ }^{2}$ Department of Pediatric Emergency Medicine, Faculty of Health Sciences, Medical University of Warsaw, Poland
}

\section{ABSTRACT}

Suicide is a major public health problem that affects people of all ages, including children. A child's decision to commit suicide is influenced by many social and psychological factors, as well as mental illness and addiction. Aim of this paper is to discuss the large scale of suicidal behaviors among children and adolescents, to select the most common causes and methods of suicide and to present a practical approach to the problem. For this purpose comprehensive review of the literature has been conducted. The most common suicide methods among children and adolescents are: hanging, jumping from a height and poisoning. According to the existing studies, quick reaction in the event of a suicide attempt is essential. The key to life-saving moment is a proper guidance of the child in the emergency department. Children after suicide attempts require long-term care, in which many people are involved like doctors, nurses and parents.

KEY WORDS:

adolescent, suicide, child, attempted suicide.

\section{INTRODUCTION}

Suicide is deliberately taking your own life. It is a serious public health problem that affects people of all ages. A suicide attempt is defined as an independent, potentially lethal act with the intent to lead to its own death, which, however, eventually does not occur. The World Health Organization (WHO) reports that suicide is a multidimensional phenomenon, resulting from the interaction between genetic, biological, sociological, psychological and environmental factors. Suicidal behaviors include thoughts of suicide, attempted suicide and death [1]. Suicides are divided into two basic groups: committed suicides resulting in killing oneself and unfinished (attempted), not resulting in suicides, due to the occurrence of circumstances that make it possible to rescue or carry out a plan in a way that ensures salvation. Suicidal behaviors also include the so-called attempted suicides, the number of which exceeds the committed suicides. It is often emphasized that attempted suicide is a cry for help.

The aim of the study is to discuss the large scale of suicidal behaviors among children and adolescents, to select the most common causes and methods of suicide and to present a practical approach to the problem. The databases Pubmed, Scopus, Web of Science and Google Scholar were reviewed and based on the keywords corresponding to those from the study, articles from the last five years on the issue of suicide attempts in children and adolescents were selected from the journals with the objectively highest Impact Factor indices, resulting in a total of 89 publications. Subsequently, all of them were read and analyzed, as well as the source articles constituting the factual basis of these texts. The most important books on child psychiatry published in Poland in the last ten years, as well as state legal acts were also read. Finally, the 45 most relevant publications about risk factors, frequency of suicidal behavior among children and adolescents, suicide

\section{ADDRESS FOR CORRESPONDENCE:}

Jan Stachurski, Department of Pediatric Emergency Medicine, Faculty of Health Sciences, Medical University of Warsaw, Poland, e-mail: jan.stachurski@wum.edu.pl 
methods and possible methods of suicide prevention were analyzed.

Suicide attempts by children and adolescents are currently a major problem in society. Childhood suicides, while statistically rarely compared to other age groups worldwide, have increased and caused a stir as it is seen as a more tragic event than an adult's suicide [2, 3]. It also causes economic problems for the country given the reduced number of economically active young adults in the future [2]. Prevalence rates for suicidal ideation range between $19.8 \%$ and $24.0 \%$ among youth [4]. Suicide is responsible for $8.5 \%$ (range 15-29 years) of deaths among young people worldwide [5-7]. In 2013, the suicide rate for the 15-19 year old age group of the 28 European Union (EU) countries surveyed was 4.51 per 100,000 [7]. The report of the Polish Police shows that in 2018 there were 11,167 suicide attempts, including 772 children. In the age group 0 to 6 , no suicide attempt was made, while in the age group 7 to 12 , there were 26 of them. In the age group from 13 to 18 , as many as 746 teenagers committed suicide attempt [8]. Actions that ended with death were mostly caused by hanging, jumping from a height, and throwing himself under a moving vehicle. The most common confirmed reason for committing the suicide was a mental illness or disorder and misunderstandings or domestic violence [7-9]. However, it should be emphasized that the Police statistics include mainly the most extreme cases, meaning successful suicides or attempts which required the police intervention, so the real population of people that experienced a suicide attempt is certainly much higher. American data indicate that it should be expected that the number of suicide attempts is 50 to even 150 times greater than the number of committed suicides $[10,11]$.

Keeping children mentally healthy is important because many people who have ever considered or attempted suicide in adulthood had suicidal thoughts for the first time in childhood or before the age of 25 [12]. The problems that can lead to a suicide decision are completely different for each age group. Events and situations that would not be treated as problems by an adult may not be solvable for young people. In 2007, WHO lists among the most common causes of suicide in children and adolescents population the following elements: family problems, separation from friends or sympathy, death of a loved one, breaking a love relationship, conflicts with the law, peer pressure, bullying, disappointment with academic performance, high level of school requirements, poor family financial situation, unwanted pregnancy, serious physical illness or infection with a sexually transmitted disease. Many comorbid factors contribute to a suicide decision [13]. The evidence underscores the complexity of suicides and points to an interaction of factors contributing to suicidal behavior. Factors that determine suicidal behavior among children and adolescents can be divided into three types: social factors, psychological factors, also mental diseases and addictions [8] (Fig. 1).

Family. There are three groups of factors whose occurrence in the family increases the risk of committing suicide: not enough love, conflicts between parents and possessive love. The rejection and neglect of a child may lead to a suicide attempt in the future. Stressful situations in the family may be the fact of raising a child by one parent who is overprotective of the child or devotes too little attention to the child. Parents' divorce is also a big problem, because the child in this situation feels confused, anxious and fearful, which results in aggressive behavior. Physical or psychological violence at home, whether against a child or another family member, also adversely affects the mental state of a young person [14]. Psychological abuse is the most common type of violence against children and destroys his image. Psychological violence is considered to be a humiliation in front of others, slander,

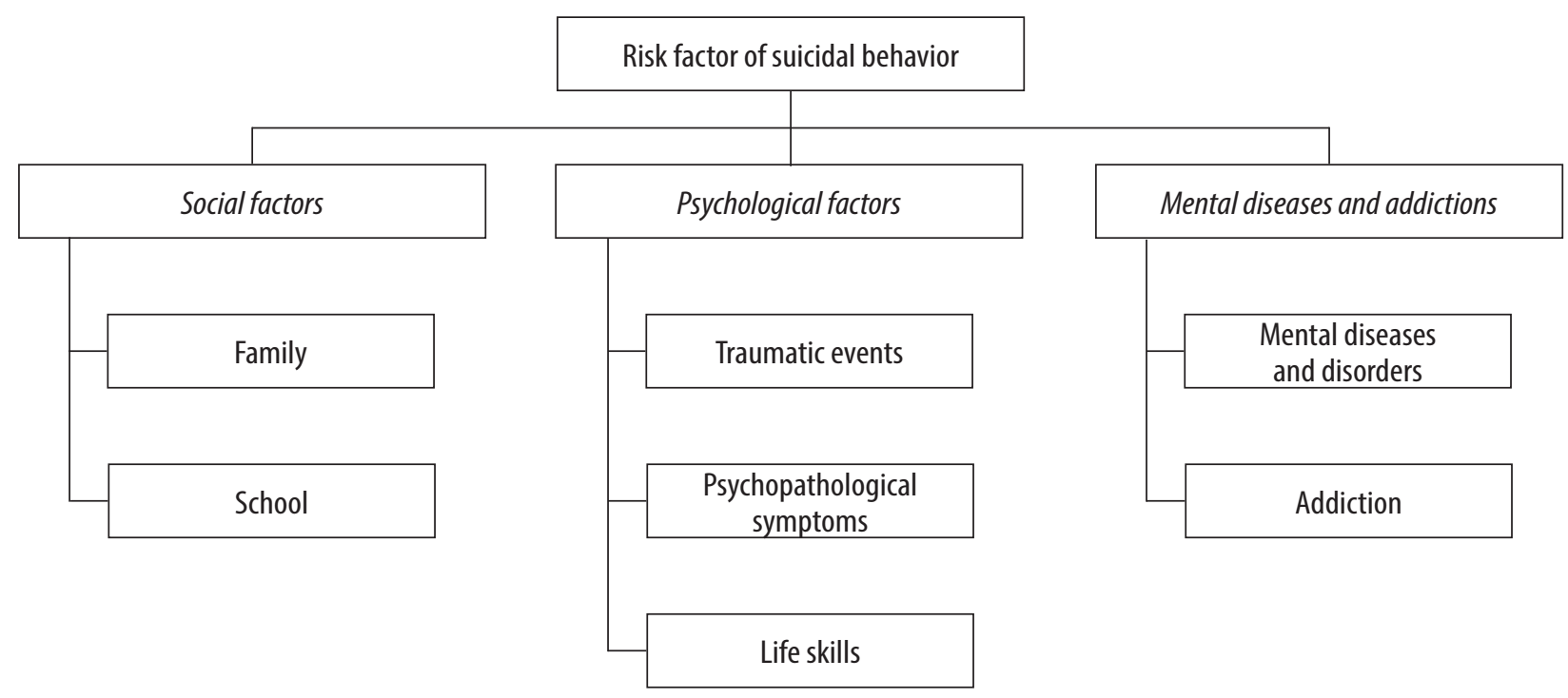

FIGURE 1. Risk factors of suicidal behavior 
discrimination, intimidation, treating a child as inferior, ridiculing, rejecting as well as other forms of negative treatment [15]. Violence against a child, although less frequently, may also manifest itself in sexual abuse by family members or people from their immediate vicinity [1].

School. Going to school affects your child's physical, mental and social development. Among the circumstances that may influence the formation of suicidal behavior, the following should be mentioned: conflicts with peers, difficulties with acquiring knowledge, the threat of improving the class, school results too low in relation to the child's ambitions or parents' expectations. Such children often show an aversion to school.

Traumatic events. The risk of attempting suicide increases with the number of adverse life experiences in childhood, such as violence against the mother, divorce or separation of parents, addictions and mental illness in the family, the death of one of the parents, especially the mother, imprisonment of a family member and other types of psychological and physical harm. Many adolescents experience sexual harassment which, as a highly traumatic event, increases the risk of children's well-being and appropriate health behavior. Sexual harassment significantly increases the incidence of suicidal thoughts in children [16].

Psychopathological symptoms. Psychological factors that appear to increase the risk of suicide include depression, anxiety, drug and alcohol use, and other comorbidities and personality traits (such as neuroticism and impulsivity) [14]. Emphasizing extreme opinions and judgments by young people can contribute to rejection and the feeling of being incomprehensible. Excessive hostility and aggression as well as impulsiveness of behavior and irritability are also associated with a high risk of suicide. The 2019 study on Austrian adults suggests that autism may be related to an increased risk of suicidal behavior [17]. Falgares et al. in their work from 2018 showed that the combined influence of certain forms of dysfunctional parenting behavior during childhood and the development of rigid and dysfunctional negative personality traits may increase the risk of suicidal thoughts and behavior in adulthood [18].

Life skills. According to WHO, life skills are the ability to behave positively and to adapt, which allows a person to cope with his challenges. Life skills include: critical thinking, the ability to solve problems and make decisions, deal with stress and your emotions and communicate effectively with others. Fail to develop life skills in children and adolescents can lead to many misunderstandings and problems, which may result in suicide attempts.

Mental diseases and disorders. Most suicides in the world can be caused by mental illness. Among them, the most common diseases that increase the risk of suicide are depression, psychosis, anxiety disorders, personality disorders, eating disorders and trauma. Organic mental disorders also significantly increase the risk of sui- cidal behavior compared to the general population [19]. Eating disorders are also a big problem. Suicide attempts in people with anorexia or bulimia are not uncommon.

Addiction. Addiction is a common phenomenon in the modern world that can lead to suicidal behavior. The most frequently consumed psychoactive substance is alcohol. Drugs are also a big problem, with their diversity and the many methods of consuming them. The drugs taken by adolescents include marijuana, sedatives and hypnotics, designer drugs and various inhalants. In 2019, an analysis of 9 independent studies on the use of the Internet and social media and suicide attempts in children and adolescents was published [20]. An analysis of these studies showed that there is a direct correlation between internet and social media use and an increased risk of suicide attempt.

\section{METHODS AND PROCEDURES}

According to the Polish Police data from 2014, the most popular suicidal method is jumping from heights and the second place on the list is taking sleeping pills. Ways of committing suicide can be divided into soft and hard. Soft ways are those that are less likely to be fatal, like poisoning. Ways such as hanging, shooting with a firearm or jumping from a height are hard. By analyzing the ways of committing a suicide attack by young people much more often girls reach after soft suicide. This is because girls are more likely to attempt suicide, which usually does not end in death. Boys deciding to commit suicide usually choose the method that causes certain death. That is why the majority of suicide victims are boys (Fig. 2).

For many patients, after a suicide attempt, the hospital emergency department (ED) becomes the only place of care, therefore the development of appropriate standards of management in ED conditions will reduce the number of complications and deaths related to suicide attempts $[22,23]$. The triage process plays an important role in dealing with the child after a suicide attempt. It is performed in Anglo-Saxon countries by specialized nurses, called 'triage nurses', but in Poland - particularly by paramedics, less often by nurses. Polish regulations also allow doctors to conduct the triage, which is an exception among other countries [24]. The knowledge and skills of pediatric emergency department employees are particularly useful in prioritization of patients due to their healthcare needs, according to the severity of their injuries and the type of the treatment they require. Rapid identification of a young patient after a suicide attempt in the emergency room allows to implement the appropriate medical procedures at the right time and save his life [25]. Paramedics or nurses involved in the triage process take a brief history of the patient and make the superficial assessment to identify any immediate requirement for care [26]. Another key task of the triage is to ensure 


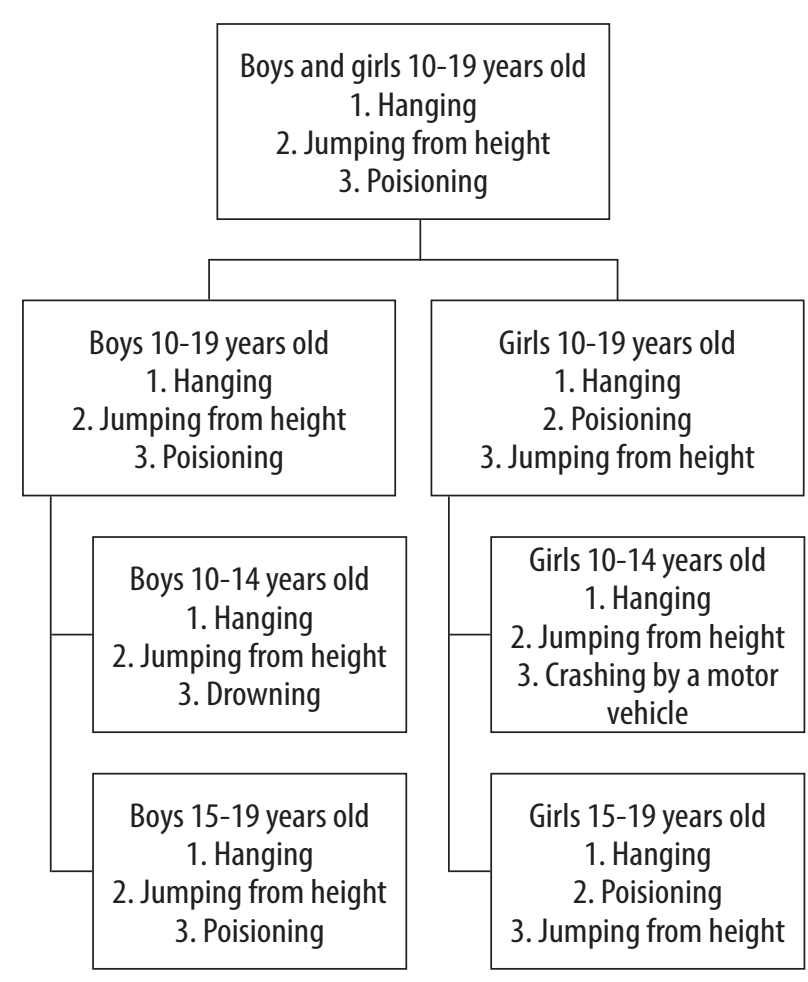

FIGURE 2. The most frequent suicidal methods depending on a gender and age, based on Napieralska E. "Epidemiology of children and adolescent suicides in Poland in 1999-2006" [19]

the safety, not only for the child, but also for people around him, and to prevent him from continuing suicidal actions. Patient should be placed in a monitored position and deprived of any dangerous tools and toxic substances. What is more, the triage procedure gives an opportunity to talk to the child and his family and provide the advice on preventing suicidal behaviors, if medical staff is not limited in terms of time [27]. According to the Manchester Triage System, children after suicide attempts are divided into four groups (not five like in other patient's problems), depending on the order of receiving specialist help. Patients marked in red are necessarily to obtain the help immediately. They are followed by those marked in orange, which are characterized especially by the high risk of further harm, manifested in patient's behavior or significant history of self-harm. Subsequently the help is received by the yellow group - the patients with marked anxiety, presence and history of psychiatric illness, inappropriate history of the current situation or moderate risk of further self-harm (among children without history of self-harm, who are not actively trying to harm themselves, but who claim to have such desires), and finally by the green group, without blue group [28].

Hanging is the most common method of committing suicide [21]. In the case of a person trying to hang himself, the airway should be cleared after the patient is cut off quickly. Depending on the symptoms, all possible life saving measures should be performed on the patient. The second most frequent type of suicide is a jump from height, which very often ends in death, but sometimes the person survives. These patients most often have a damaged spine and multi-fragment bone fractures. They may also experience spinal shock as a consequence of a complete disruption of the spine.

Deliberate self-poisoning is generally observed in older children and adolescents [29]. Girls are more likely to suffer from intentional poisoning, which is related to their tendency to choose less lethal methods of suicide [30]. This process usually occurs in the group of patients between 14 and 18 years of age and most cases of acute deliberate self-poisoning include psychoactive substances and drugs. According to the 10 -year study period, in the United States between 2004 and 2013, in the children population the most common ingested substances were acetaminophen (10.9\%), ibuprofen (9\%), selective serotonin reuptake inhibitors (7.7\%), atypical antipsychotics (6\%) and antihistamines (5\%) [29]. Easy access to various types of intoxicants and the popularity of the topic in the Internet and social media are important factors influencing the size of this problem $[20,30]$.

Toxic substances can affect all tissues of the body, including the nervous system. The action of certain toxins on its structures can lead to the development of a complex of specific clinical symptoms called toxidrome. The key goal is to determine the correct toxidrome so as to find the likely cause of the poisoning. Emergency department employees should also enquire about the dosage and timing of overdose [31,32]. Combining drugs with alcohol, and sometimes also with another suicide method is a grave medical problem. Specialists who work in the pediatrician emergency department rarely deal with poisoning with only one substance, most often there are mixtures of drugs $[22,33]$. Those situations lead to overlapping somatic symptoms and difficulty in selecting a treatment method, especially when the interview with the patient is impossible to collect or unreliable [14]. The mortality rate is also essential in assessing the degree of risk of individual chemical substances. The highest mortality rate is recorded in poisoning with alcohol, organophosphates, tricyclic antidepressants, as well as cardiovascular drugs and narcotics. This risk increases when alcohol poisoning is used additionally. The management of a patient who has ingested a substance in a poisonous dose is based on three elements: supporting life functions, effective elimination of the toxic compound and, if possible, administration of specific antidotes. Life support process is aimed at prevention, early diagnosis and symptomatic treatment of the consequences of exposure to the poisonous compound [23].

\section{MANAGEMENT OF THE YOUTH EXPERIENCING SUICIDAL IDEATION}

The first step in treating a child after a suicide attempt is a control of the vital signs of the patient. The priority is to reverse the life-threatening condition, and then to treat 
the disease, taking into consideration its probable cause. Choice of the first aid method and appropriate management during the initial steps of stabilization of vital functions in the emergency department are essential for the results of treatment [23]. Consultation of a psychiatry specialist should be ordered when the somatic state of the patient allows for direct contact with him.

In order to be able to make a proper scheme of effective treatment for a child after a suicide attempt, it is necessary to assess the degree of risk of next suicide attempt and identify the factors that contributed to it $[14,30]$. This process requires an interview with the child and its parents or guardians [31]. It is necessary to ask about history of suicide attempts and mental disorders in the family and also about any other family problems, especially depression, substance abuse, parental divorce or separation and poor communication between children and parents [34, 35]. However, the young patient should be interviewed separately from the parent, because this space could encourage him to share important information in the parent's absence. Unfortunately, it is not always possible, because in accordance with the applicable legal regulations, all actions taken with regards to young patients require parental approval [36]. The circumstances of the doctor's interview with the child must be agreed with the parents, and in some cases they may not allow to leave the child alone as they have the right and duty to know what is happening to him in every second of his staying in the emergency room [37]. It is worth noting that despite the fact that such a possibility is guaranteed by law, legal guardians not leaving the examination room upon an explicit request of the doctor, may be interpreted as a sign of disturbed family relations and violent phenomena: neglect, physical and psychological aggression or sexual abuse. A parent using violence against a child in such a situation will try to hide the real reason for the child's suicidal behaviour in order to avoid criminal responsibility, so the interview may turn out to be misleading and incomplete. Another "red flag" indicating family problems may also be a significant change in the child's behaviour in the presence of the parent and once the parent leaves the room. Initially apathetic or shaken, the child calms down after the parent leaves the examination room [38].

The inquiry should include the characteristics of a present suicide attempt, current and past suicidal behavior, assessment of the mental state, psychological portrait of the child, assessment of relates between family members and question about sexual orientation [30]. According to researches lesbian, gay, bisexual, transgender and questioning (LGBTQ) children and adolescents are in higher risk of developing suicidal ideation than heterosexual [1]. The interview should also determine whether the child's environment is not a threat to him, for example because of the poor parental supervision, mental illness or addiction of parents or the availability of drugs, poisons and weapons. The characteristic of a suicide attempt requires gathering information about the circumstances of the incident, risk assessment of the method and knowledge how serious he or she has felt about dying [30]. Questions about suicide are not claimed to be an acceleration factor in terms of the suicidal behavior even to high-risk children [33]. Patient's history might be helpful while assessing intensity of suicidal intentions, one of the useful indicators for clinical intervention [39]. The following circumstances indicate the seriousness of the situation: acting in isolation, at a deliberately chosen time, in conditions that make it difficult to intervene from outside, earlier preparations [9].

The risk of suicidal behavior grows with an increasing number of risk factors, some of which are at greater risk than others, such as psychiatric and mood disorders, specific personality characteristics, genetic disorders along with family processes in combination with triggering psychosocial stressors and mostly: previous suicide attempts and history of self-harm $[34,35]$. Therefore, an important role is played by mental status testing, which aims to assess the risk of a repeated suicide attempt (whether it is a current or distant risk) and to determine the factors preceding and triggering suicidal behavior. It is necessary to extract the subgroups of children, including those with a history of multiple episodes of suicide attempts and those with a single or only few episodes [39]. The child is also investigated in terms of coexisting mental disorders, mainly depression, borderline, schizophrenia, anxiety and psychotic states, bulimia, anorexia nervosa or other personality and behavior disorders [30,34].

A number of diagnostic tools are used to identify children and adolescents at high risk of suicidal behavior, but the gold standard procedure, which could be helpful in evaluation of young patients experiencing suicidal ideation, is a Columbia-Suicide Severity Rating Scale (C-SSRS) [40]. The assessment is based especially on patient responses to screening questions, but also on information collected from their family, healthcare professionals and medical records and it helps to divide them into categories of low, moderate or high suicidal risk [41]. The scale was designed mainly to distinguish suicidal ideation and suicidal behavior. The questions relate to four aspects: severity of ideation (which include desire to be dead, nonspecific active suicidal thoughts, suicidal thoughts with methods, suicidal intent and suicidal intent with plan), the intensity of ideation (frequency, duration, controllability, deterrents and reasons for thoughts are assessed), characteristics of suicidal behavior (actual, interrupted and aborted attempts, as well as preparatory acts or behavior) and finally the lethality, actual and potential [42].

The information collected in the interview is used to develop a therapeutic strategy. Treatment of a patient who reveals suicidal behavior should always be adjusted to his individual characteristics, age, psychopathology and 
his and his family's problems. The following options are considered: brief crisis intervention, observation during hospitalization in a pediatric department, transfer to a psychiatric department for children and adolescents or referral to a mental health clinic after discharging from the pediatric department [22]. Brief crisis intervention is implemented when the patient is hospitalized in the pediatric department, after discharge from the emergency department and before transfer to a psychiatric hospital. It is a series of interdisciplinary actions, mainly psychological or, less frequently, social or legal assistance, aimed at providing the child with emotional support and an opportunity to relieve tension, as well as at restoring the patient's mental balance and ability to cope with the current problem independently, and learning the skills to overcome suicidal thoughts and tendencies in the future. Such actions may also concern the patient's relatives and serve then to mobilize the family to restore the child's sense of security and strengthen family ties in order to prevent further suicidal behaviour $[1,43]$. The decision to treat at the clinic should be made when the specialist consultation has clarified the reasons for a suicide attempt and ruled out the presence of domestic violence. In many cases, a stay in a psychiatric ward is not absolutely necessary and the patient may be treated on an outpatient basis. It is possible when there is no current risk of the next try and the family has engaged in solving the child's problems. An important element of the therapy is intervention in the child's school environment [7]. Outpatient care includes family psychoeducation on suicidal behavior and psychotherapy, group-based or individual. Ougrin et al. in their study from 2015 revealed that the most effective psychological therapeutic interventions are cognitive-behavioral therapy, dialectal behavior therapy and mentalization-based therapy [44]. In addition to the non-pharmacological treatment of accompanying mental disorders, sometimes appropriate drugs (like antidepressants, antipsychotics or mood stabilizers) should also be ordered. Pharmacological therapy is particularly important when the patient has been diagnosed with psychiatric disorders [30,39]. Another possible stage of treatment of a child after a suicide attempt is a psychiatric hospitalization. It could help to develop the diagnosis and establish a treatment plan. Patients' stay in the hospital may be also related to the isolation from the possible factors that could cause suicidal behavior [31].

\section{PREVENTION}

Wide prophylaxis of risky behaviors play an extremely important role in suicide prevention among children and adolescents [22]. The family, school, health care system, police and national administration should be involved in preventive activities [8]. The effectiveness of this process depends mostly on the group of recipients which are supported [9]. Strategy of the prevention of suicide consists of five steps. The first level is related to the whole society. It is focused on learning people how to accept their life and acquiring antisuicidal attitudes, and also developing problem-solving skills. Those population-based actions should include mental health promotion and education programs, awareness by campaigns on mental resilience, limiting the physical availability of means of committing suicide and careful media coverage [34]. At second level it is necessary to make an impact in the population that may potentially be at risk of suicidal attitudes. The third level is to help a child who has been identified as having a high risk of committing suicide. At level four there is acting in a suicidal situation that serves to restore the individual who committed the suicide attack to motivation for further life. And finally, at level five: post-suicidal influence involves the suicidal patient and his family $[1,8]$.

The family is key in a proper development of a child and the prevention of inadequate attitudes. The risky behaviors that are manifested by adolescents begin at a very young age. A reaction at an early stage of a child's growth gives a good chance of stopping difficulties [8]. Parents should be focused on children's issues, talk to them and try to solve the child's problem together. As long as they are careful observers, they can find specialist help for their child in an appropriate moment. School also plays an essential role in preventing suicide in children and adolescents. Teachers should be trained in how to recognize the needs and problems of children, create a safe school environment and raise students' self-confidence, as well as identify people to whom they can turn to for advice and help. Suicide prevention strategies at school include: universal programs addressed to all of the students which aim to educate them about risk, selective prevention strategies countering a risk factor shared within a specific groups of children (students with health, economic and family problems or presenting the learning difficulties) and indicated prevention interventions addressed to students from extremely high-risk groups, who are not formally diagnosed or in-treatment, but have the history of suicide attempts or take psychoactive substances [1]. Post-suicidal help, for example preventing recurrence of suicide behaviors in children who have attempted suicide in the past, should be focused on the person who tried to take their own life, as well as on their family. They all should have easy access to therapy and psychological support guaranteed $[8,19]$.

Not only psychiatry specialists, but also nurses and pediatricians should pay special attention to patients with potential suicidal tendencies. In children and adolescents serious mood disorders may be presented in several ways. They can suffer from similar syndromes to adults such as sad, guilty or worthless feelings most of the time, crying spells, diminished interest or pleasure in most activities, increase or decrease in appetite, insomnia or hypersomnia, fatigue or significant weight loss. Irritability rather than depressed mood could be considered as 
a main symptom of a mental disorder for some adolescents. Other children can suffer from somatic symptoms, such as chest and abdominal pain, lethargy, weight loss, headache, dizziness and syncope or other nonspecific symptoms. It suggests that symptoms of depression or other psychiatric disorders are not immediately obvious and nurses and pediatricians should be extremely careful in observations, diagnosis and management with young patients [30].

Moreover, examination of a child at the emergency department gives the opportunity to recognize that the child is a victim of violence [15]. Prevention of such attitude is truly essential due to the fact that adolescent victims are more likely to experience suicidal thoughts and attempts [16, 35]. Early identification of symptoms of violence against a child can save the child's life. Pediatricians should not struggle with diagnosing the musculo-skeletal injuries, especially bone fractures that do not typically occur in the age of a patient. Bloody streaks on the child's body, torn auricles, nose deformities, hair loss, blunt or cut skin wounds may also be presented [26]. The liver, spleen and kidneys can be injured due to kicking or hitting. When the physical signs of violence are not observed, changes in the child's behavior may be suggestive. Children can react with apathy or depression or may be hyperactive, emotionally unstable and display behavioral disturbances, aggression towards other children, adults or themselves. However, all these behaviors are not very specific and should be interpreted very carefully, especially in the lack of evidence in a physical examination. It should be remembered that in case of suspicion of child abusement, examination of the veins in the eyes, computed tomography of the central nervous system and abdominal ultrasound can be ordered $[15,18]$. In Poland, in the case of a justified suspicion of violence against a child by a family member, under the Act on Counteracting Family Violence of 29 July 2005, health care professionals have the possibility to initiate the 'Blue Card' procedure or to ask the Family Court to review the family's situation. In addition, they should also provide the person suspected of being a victim of violence with information about the possibility of obtaining assistance and the right to a forensic examination $[15,45]$.

\section{CONCLUSIONS}

A child's suicide attempt is a decision that involves many factors. It is rarely based on a single impulse. Mostly, it is the result of the long-term build-up of problems and fears. Early noticing the problems of children and adolescents and quick help are very important in reducing the number of suicide attempts. Restricting access to the most common suicide methods and common risk factors (e.g. alcohol, drugs, the Internet) can be an important suicide prevention strategy. Adequate childcare after an attempted suicide is just as important as preventing suicidal behavior. The problem of suicides among children is an interdisciplinary issue, the effective solution of which should be addressed by many people (this applies, among others, to nurses, pediatricians, psychologists, teachers, child psychiatrists and parents).

\section{DISCLOSURE}

The authors declare no conflict of interest.

\section{REFERENCES}

1. Cha CB, Franz PJ, Guzman EM, et al. Annual Research Review: Suicide among youth - epidemiology, (potential) etiology, and treatment. J Child Psychol Psychiatry 2018; 59: 460-482.

2. Sousa GS, Santos M, Silva A, et al. Suicide in childhood: a literatura review. Cien Saude Colet 2017; 22: 3099-3110.

3. Weller EB, Young KM, Rohrbaugh AH, et al. Overview and assessment of the suicidal child. Depress Anxiety 2001; 14: 157-163.

4. Nock MK, Borges G, Bromet EJ, et al. Suicide and suicidal behavior. Epidemiol Rev 2008; 30: 133-154.

5. Kokkevi A, Rotsika V, Arapaki A, et al. Adolescents' self-reported suicide attempts, self-harm thoughts and their correlates across 17 European countries. J Child Psychol Psychiatry 2012; 53: 381-389.

6. Steele MM, Doey T. Suicidal behaviour in children and adolescents. part 1: etiology and risk factors. Can J Psychiatry 2007; 52 (6 Suppl 1): 21-33.

7. Laido Z, Voracek M, Till B, et al. Epidemiology of suicide among children and adolescents in Austria, 2001-2014. Wien Klin Wochenschr 2017; 129: 121-128.

8. Kołodziej K, Jarek K, Murzyn M, et al. Uwarunkowania zachowań samobójczych dzieci i młodzieży. Pielęgniarstwo Polskie 2020; 78: 203-208.

9. Raniszewska-Wyrwa A. Problem samobójstw w perspektywie psychiatrycznej i psychologicznej. Acta Universitatis Lodziensis Folia Psychologica 2010; 14: 45-62.

10. Shain B. Suicide and Suicide Attempts in Adolescents. Official Journal of the American Academy of Pediatrics 2016; 138: e20161420.

11. Husain SA. Current Perspective on the Role of Psychosocial Factors in Adolescent Suicide. Psychiatric Annals 1990; 20: 3.

12. Kessler RC, Borges G, Walters EE. Prevalence of and risk factors for lifetime suicide attempts in the National Comorbidity Survey. Arch Gen Psychiatry 1999; 56: 617-626.

13. Kielan A, Olejniczak D. Czynniki ryzyka oraz konsekwencje zachowań samobójczych z uwzględnieniem problematyki samobójstw dzieci i młodzieży. Dziecko Krzywdzone Teoria, Badania, Praktyka 2018; 17: 9-26.

14. Carballo JJ, Llorente C, Kehrmann L, et al. Psychosocial risk factors for suicidality in children and adolescents. Eur Child Adolesc Psychiatry 2020; 29: 759-776.

15. Wantuch D, Stopa S, Piękoś D, et al. Przemoc wobec dzieci. Czy zespół ratownictwa medycznego może rozpoznać zagrożone dziecko? Anaesthesiology \& Rescue Medicine/Anestezjologia i Ratownictwo 2017; 11: 465-471.

16. de Lijster GP, Felten H, Kok G, et al. Effects of an Interactive School-Based Program for Preventing Adolescent Sexual Harassment: A Cluster-Randomized Controlled Evaluation Study. J Youth Adolesc 2016; 45: 874-886.

17. Richards G, Kenny R, Griffiths S, et al. Autistic traits in adults who have attempted suicide. Mol Autism 2019; 10: 26.

18. Falgares G, Marchetti D, Manna G, et al. Childhood Maltreatment, Pathological Personality Dimensions, and Suicide Risk in Young Adults. Front Psychol 2018; 9: 806. 
19. Bachmann S. Epidemiology of Suicide and the Psychiatric Perspective. Int J Environ Res Public Health 2018; 15: 1425.

20. Sedgwick R, Epstein S, Dutta R, et al. Social media, internet use and suicide attempts in adolescents. Curr Opin Psychiatry 2019; 32: 534-541.

21. Napieralska E, Kułaga Z, Gurzkowska B, et al. Epidemiology of children and adolescent suicides in Poland in 1999-2006. Probl Hig Epidemiol 2010; 91: 92-98.

22. Ting SA, Sullivan AF, Boudreaux ED, et al. Trends in US emergency department visits for attempted suicide and self-inflicted injury, 1993-2008. Gen Hosp Psychiatry 2012; 34: 557-565.

23. Chun TH, Katz ER, Duffy SJ, et al. Challenges of managing pediatric mental health crises in the emergency department. Child Adolesc Psychiatr Clin N Am 2015; 24: 21-40.

24. Regulation of the Minister of Health dated from 27 June 2019 concerning Emergency Departments. In: Journal of Laws of the Republic of Poland, Warsaw 1 July item 1213.

25. Rehman SA, Ali PA. A review of factors affecting patient satisfaction with nurse led triage in emergency departments. International Emergency Nursing 2016; 29: 38-44.

26. Rutledge TR, Merritt LS. Pediatric Nurse Practitioners in the Emergency Department: Implications for Education and Research. Journal of pediatric health care: official publication of National Association of Pediatric Nurse Associates \& Practitioners 2017; 31: 729-733.

27. Neades BL. Expanding the role of the nurse in the Accident and Emergency department. Postgraduate Med J 1997; 73: 17-22.

28. Mackway-Jones K, Marsden J, Windle J. Emergency triage/Manchester Triage Group. John Wiley and Sons, Ltd. Chichester 2014; 142-143.

29. Sheridan DC, Hendrickson RG, Lin AL, et al. Adolescent Suicidal Ingestion: National Trends Over a Decade. The Journal of adolescent health: official publication of the Society for Adolescent Medicine 2017; 60: 191-195.

30. Shain B. Suicide and Suicide Attempts in Adolescents. Pediatrics, 2016; 138: e20161420.

31. Kraemer S. Deliberate self-poisoning by teenagers. Archives of Disease in Childhood 2019; 104: 728-729.

32. Zakharov S, Navratil T, Pelclova D. Suicide attempts by deliberate self-poisoning in children and adolescents. Psychiatry Res 2013; 210: 302-307.

33. Gould MS, Marrocco FA, Kleinman M, et al. Evaluating iatrogenic risk of youth suicide screening programs: a randomized controlled trial. JAMA 2005; 293: 1635-1643.

34. Bilsen J. Suicide and Youth: Risk Factors. Frontiers in psychiatry 2018; 9: 540

35. Soole R, Kõlves K, De Leo D. Suicide in Children: A Systematic Review. Archives of suicide research: official journal of the International Academy for Suicide Research 2015; 19: 285-304.

36. Augustynowicz A, Wrześniewska-Wal I, Dykowska G, et al. Uprawnienia opiekuna faktycznego w procesie diagnostyczno-terapeutycznym podejmowanym wobec małoletniego pacjenta - wybrane zagadnienia prawne. Pediatria Polska 2016; 91: 180-184.

37. Haberko J. Sytuacja prawna dziecka jako pacjenta. Dziecko Krzywdzone Teoria, Badania, Praktyka 2020; 19: 11-27.

38. Tiyyagura G, Gawel M, Koziel JR, et al. Barriers and facilitators to detecting child abuse and neglect in general emergency departments. Ann Emerg Med 2015; 66: 447-454.

39. Hawton K, Witt KG, Taylor Salisbury TL, et al. Interventions for self-harm in children and adolescents. Cochrane Database Syst Rev 2015; (12): Cd012013.

40. https://cssrs.columbia.edu/. The website of the Lighthouse project with numerous translations of the C-SSRS scale along with the screening and the full version.
41. Salvi J. Calculated Decisions: Columbia-Suicide Severity Rating Scale (C-SSRS). Emerg Medicine Pract 2019; 21: Cd3-Cd4.

42. Posner K, Brown GK, Stanley B, et al. The Columbia-Suicide Severity Rating Scale: initial validity and internal consistency findings from three multisite studies with adolescents and adults. Am J Psychiatry 2011; 168: 1266-1277.

43. Bąbik A, Olejniczak D. Uwarunkowania i profilaktyka samobójstw wśród dzieci i młodzieży w Polsce. Dziecko Krzywdzone Teoria, Badania, Praktyka 2014; 13: 99-121.

44. Ougrin D, Tranah T, Stahl D, et al.; Therapeutic interventions for suicide attempts and self-harm in adolescents: systematic review and meta-analysis. Journal of the American Academy of Child and Adolescent Psychiatry 2015; 54: 97-107.e2.

45. Act on Counteracting Family Violence dated from 29 July 2005. In: Journal of Laws of the Republic of Poland, Warsaw 2005 item 1493. 